\title{
Chronic encapsulated intraventricular hematoma in a pediatric patient: case report
}

\author{
Jeremy Wetzel, MD, ${ }^{1}$ David Bray, MD, ${ }^{1}$ and David Wrubel, MD² \\ ${ }^{1}$ Emory University School of Medicine, Department of Neurosurgery; and ${ }^{2}$ Children's Healthcare of Atlanta, Egleston Hospital, \\ Department of Neurosurgery, Atlanta, Georgia
}

\begin{abstract}
Chronic encapsulated intraventricular hematoma (CEIVH) is a rare, intraventricular, nonneoplastic mass lesion that can become symptomatic from mass effect or obstructive hydrocephalus. Only 5 cases have been reported in the literature, and only one of these occurred in a pediatric patient and dates back to the pre-modern neuroimaging and pre-microsurgical era of neurosurgery. Imaging features can mimic those of many more common intraventricular lesions, such as choroid plexus tumors or cavernous malformations. In all reported symptomatic cases, resection was safely performed and led to a cure and symptom resolution. Here, the authors present a case of CEIVH in a pediatric patient, describe the operative techniques of resection, review the available literature, and discuss current understanding of the pathophysiology, making this the most comprehensive report on this disease entity to date. The case is a 14-year-old boy who presented with headaches and emesis. Computed tomography showed a hyperdense mass in the trigone of the right lateral ventricle. Magnetic resonance imaging showed a contrast-enhancing well-circumscribed mass. Right temporal craniotomy utilizing a posterior middle temporal gyrus transcortical approach was performed, and gross-total resection was achieved. Pathology revealed a CEIVH. The boy's postoperative course was uncomplicated, and he was discharged 2 days after surgery.

https://thejns.org/doi/abs/10.3171/2018.1.PEDS17585
\end{abstract}

KEYWORDS intraventricular; chronic encapsulated hematoma; pediatric; vascular disorders

$\mathrm{C}$

HRONIC encapsulated intracerebral hematoma $(\mathrm{CEIH})$ is a rare, solid, nonneoplastic, well-circumvariety of signs and symptoms depending on the location of the lesion. First defined by Hirsh et al., CEIH can mimic neoplasms or vascular malformations in its presentation and radiological findings and is often distinguishable only on pathological examination of resected tissue..$^{10}$ Approximately 60 cases of CEIH have been reported in the literature, and by far the majority of them are intraparenchymal in location.22

To our knowledge, only 5 cases of chronic encapsulated intraventricular hematoma (CEIVH) have been reported in 4 papers. ${ }^{2,6,13,23}$ Of these, only 1 case has occurred in a child; however, its report dates back to $1955 .^{2}$ The etiology of these lesions is not well defined. Here, we present the case of a chronic encapsulated hematoma of the trigone of the right lateral ventricle in a patient who presented with headaches. To our knowledge, this is the most comprehensive report on this lesion, supplemented with intraoperative photographs and video, as well as a review of the literature. Furthermore, it is the first report of a CEIVH mimicking a neoplasm in a pediatric patient in the modern era of neurosurgery.

\section{Case Report}

Clinical Presentation

A 14-year-old, previously healthy male presented with 2 days of right-sided headache, blurred vision, nausea, and vomiting. He had a normal neurological exam. No papilledema was noted. The patient was having intermittent

ABBREVIATIONS $\mathrm{CEIH}$ = chronic encapsulated intracerebral hematoma; $\mathrm{CEIVH}=$ chronic encapsulated intraventricular hematoma. 

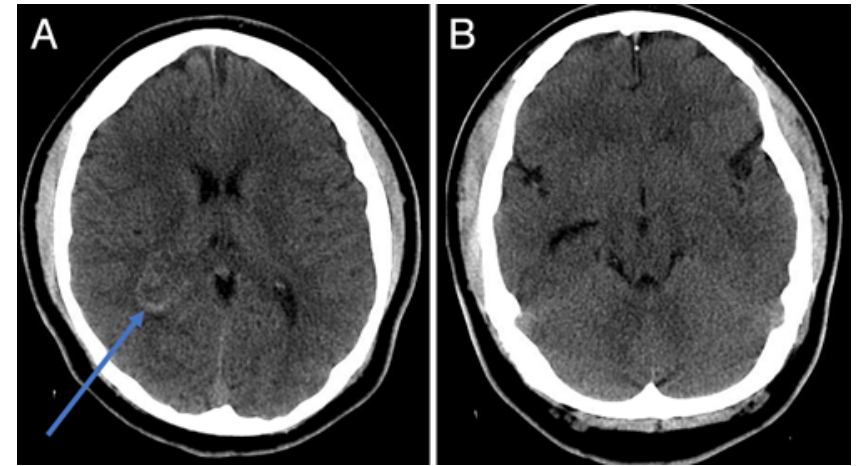

FIG. 1. Preoperative CT scans demonstrating an isodense mass within the trigone with peripheral hyperdensity (arrow, A) and early entrapment of the right temporal horn (B). Figure is available in color online only.

high fevers $\left(>39^{\circ} \mathrm{C}\right)$ while in the hospital prior to surgery. Full infectious workup was negative, and the significance of the fevers was unclear. There was no history of trauma preceding his presentation. He had no personal or family history of any coagulopathy or bleeding diathesis. His laboratory workup, which included a complete blood count, basic metabolic panel, and standard coagulation tests, was unremarkable. Given the exclusion of any personal identifying information pertaining to this case, specific permission from this patient was neither required nor sought. No institutional review board approval was indicated to produce this case report and literature review.

\section{Imaging Examination}

Head CT without contrast revealed an isodense mass in the trigone of the right lateral ventricle with surrounding hyperdensity (Fig. 1A). There was enlargement of the right temporal horn indicating early entrapment and suggesting that the patient's headaches were indeed related to the presence of this mass (Fig. 1B)

Gadolinium-enhanced MRI revealed a $2.9 \times 2.2 \times 2.4-$ $\mathrm{cm}$ mass that was T1 hypointense, T2 isointense, avidly contrast enhancing, and non-diffusion restricting (Fig. 2). Magnetic resonance angiography did not show any obvious vascular malformation. Given these imaging characteristics, we believed that this probably represented a choroid plexus tumor, favoring a papilloma or, less likely, an intraventricular cavernous malformation.

\section{Operation}

Given the diagnostic uncertainty and early entrapment of the temporal horn, resection was recommended to the patient and his family. He was taken for a temporal craniotomy for image-guided resection of the mass. A posterior middle temporal gyrus transcortical approach was employed to gain access to the posterior part of the temporal horn, which in turn provided access to the atrium. Upon entering the ventricle, we encountered normal-appearing choroid plexus of the atrium, which was partially overlying, but separate from, the mass. The lesion appeared as a well-demarcated bluish-gray mass with a thick capsule, which was well vascularized (Fig. 3A). It had feeding and draining vessels from a relatively normal-appearing cho-
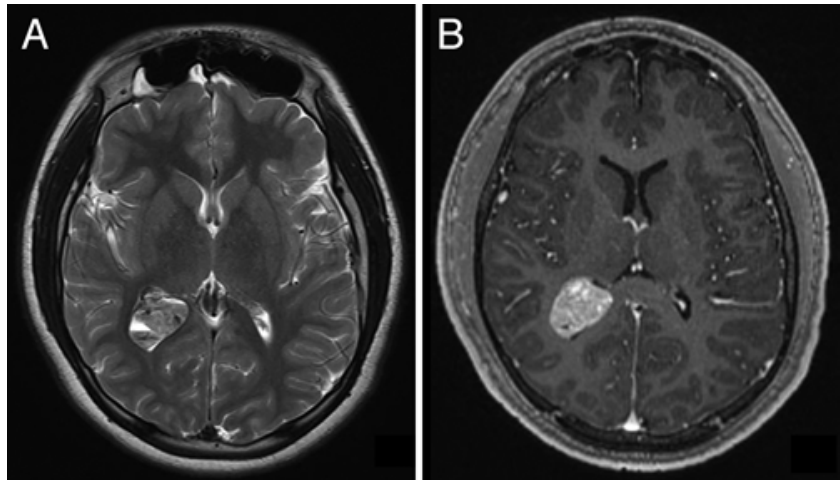

FIG. 2. Preoperative MR image (A) showing a T2 isointense lesion within the right trigone with relative dilatation of the trigone. Preoperative contrast-enhanced T1-weighted MR image (B) showing heterogeneous enhancement.

roid plexus. There was a robust vascular pedicle attached to the lesion (Fig. 3B). This was likely the choroidal artery feeding the glomus of the choroid plexus, but it may have been supplying the lesion as well. Initially, the capsule was coagulated and opened sharply, revealing a chronic liquefied dark brown hematoma (Video 1).

VIDEO 1. Intraoperative video of resection of a CEIVH. Copyright Jeremy Wetzel. Published with permission. Click here to view.

The mass was circumferentially dissected, and it separated easily from the ependymal surface, which was hemosiderin stained. The vascular pedicles were coagulated and cut, and the mass was removed en bloc.

\section{Postoperative Course}

The patient was discharged on postoperative day 3 . He suffered no neurological deficit. Postoperative MRI revealed gross-total resection (Fig. 4). Interestingly, he had at least two temperatures recorded as $>39^{\circ} \mathrm{C}$ each day prior to surgery and not a single temperature $>38^{\circ} \mathrm{C}$ postoperatively. Again, the significance of the fevers is unknown, but they were believed to be incidental and unrelated to the lesion.

\section{Pathological Findings}

Gross specimen examination revealed a soft, tanbrown fibrous mass. On $\mathrm{H} \& \mathrm{E}$ staining, there were regions with organized hematoma with fibroblasts (Fig. 5A). There was a choroid plexus stalk containing large blood vessels, meningothelial clusters, and a blood-filled cavity lined with hemosiderin-stained fibroblasts and chronic inflammation. Some of the large vessel walls had extensive hematoidin deposition. Psammoma bodies were seen (Fig. 5B). Cholesterol clefts appeared in areas representative of xanthogranulomatous change (Fig. 5C). No source of hemorrhage was seen. No neoplastic tissue was identified, nor were any malformed capillary caverns indicative of a cavernous malformation.

\section{Discussion}

Here, we present the first case of CEIVH in a pediatric 

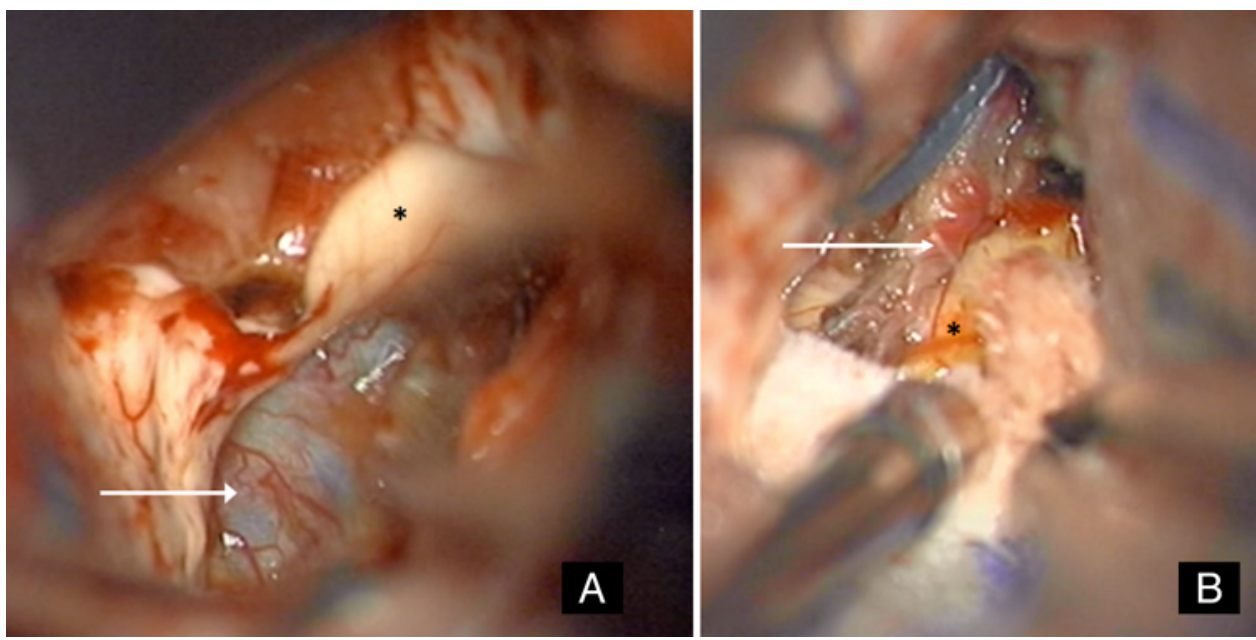

FIG. 3. Intraoperative microscope photographs. A: Intraoperative view after opening ependyma and entering the ventricle. Asterisk indicates normal ependyma. Arrow points to the lesion with its blue-gray pseudocapsule with neovascularization. B: Intraoperative view into the trigone after resection of the mass. Asterisk indicates hemosiderin-stained ependyma. Arrow points to the divided vascular pedicle, likely representing the choroidal artery.

patient in the modern neuroimaging era. ${ }^{26}$ Only 5 other cases of CEIVH have been reported in the literature (Table 1). While there are approximately 60 cases of $\mathrm{CEIH}$ in the literature, an intraventricular lesion of this sort is a rare phenomenon. Below we discuss the definition, etiology, presentation, radiological features, operative considerations, and pathology of these lesions.

Intracerebral and intraventricular hematomas are common diagnoses seen by the neurologist and neurosurgeon, generally occurring in the setting of long-standing untreated hypertension or rupture of a vascular malformation. ${ }^{11}$ Immediately after hemorrhage occurs, platelets in contact with tissue factor begin to form a clot. Ultimately, immune cells and fibroblasts migrate into the clot and initiate an inflammatory response. ${ }^{5}$ Granulation tissue forms around the hemorrhage periphery, which may contribute to the peripheral hyperdensity seen on CT. ${ }^{5,29}$

The majority of these clots go through a process whereby they become liquefied and resorbed over 6-8 months. ${ }^{9,24}$ Rarely, intracerebral hematomas will become encapsulated in a process that has been theorized to be similar to the formation of a chronic subdural hematoma. ${ }^{19,24,25}$ It is hypothesized that in the subacute phase of a slow hemorrhage, fibroblasts enter the intracerebral parenchyma and begin to form a capsule around the hemorrhage area. ${ }^{1,10}$ As the capsule wall forms, it becomes vascularized through chemical signaling shown to include vascular endothelial growth factor (VEGF). ${ }^{21,28}$ The friable vasculature of the hematoma capsule wall can rehemorrhage, further adding to the volume of the hematoma core. ${ }^{4,15-17,24}$ It is important to note that the fibroblastic capsule is critical to the definition of CEIH and CEIVH, and in the absence of this capsule a lesion is not considered as such. ${ }^{20}$

It has been postulated that one-half of all CEIHs first form due to a vascular malformation or microaneurysm. ${ }^{8}$ The typical culprit is a cavernous malformation because of its indolent, slow hemorrhage pattern, but small and cryptic high-flow malformations have also been shown to create a CEIH., ${ }^{3,14}$ The overwhelming majority of these vascular malformations are angiographically occult, but diagnosis is made after histological analysis demonstrates thin-walled sinusoids with a single level of endothelium in a cavernoma or thick and thin-walled vessels of various calibers in an arteriovenous malformation. ${ }^{3,14}$ A CEIH is a known complication after incomplete obliteration of vascular malformations in stereotactic radiosurgery. ${ }^{7,21,28}$ Other postulated causes of CEIH have included vascular amyloidosis and subclinical hemorrhage after trauma. ${ }^{18,30}$ The use of antiplatelets and anticoagulation may have a role in the progression of CEIH and CEIVH. ${ }^{6}$ Hypertension may be associated with the formation of CEIH..$^{5,16}$ No etiology is found for many cases of CEIH. ${ }^{27}$ It is a largely benign growth until it causes significant neurological deficit or mass effect. Unique to the CEIVH is the development of
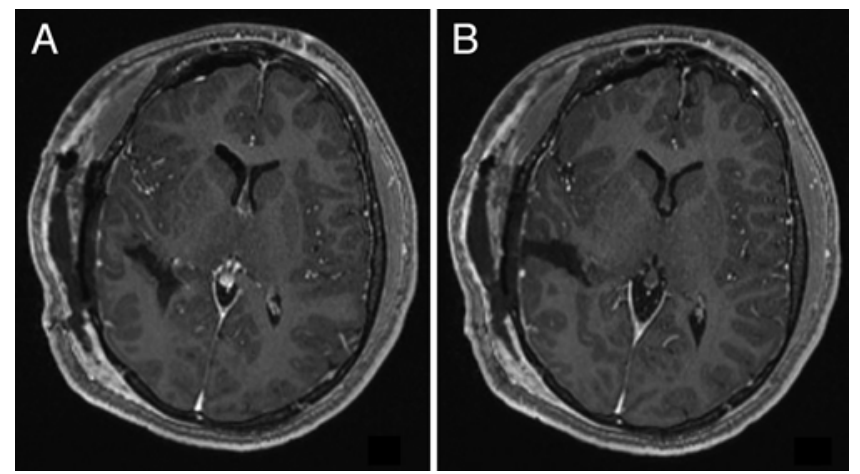

FIG. 4. A: Postoperative MR image showing total resection of the lesion. B: Postoperative MR image showing the surgical corridor to the temporal horn and atrium. 

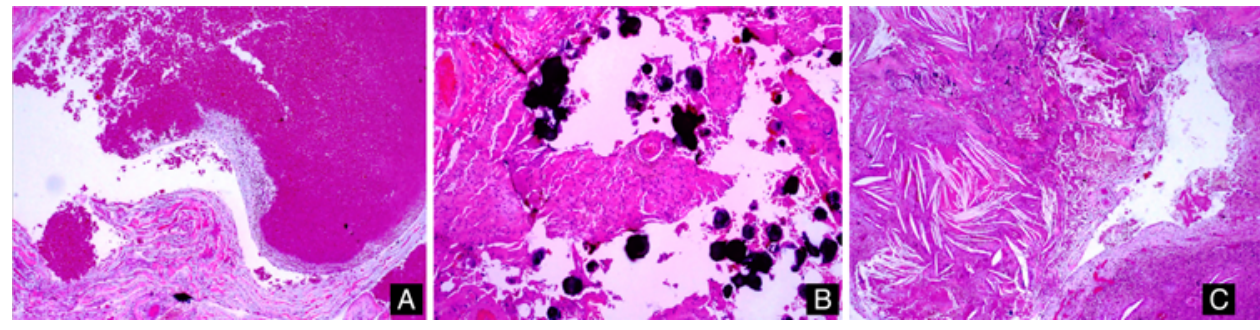

FIG. 5. Photomicrographs demonstrating an organized hematoma with infiltrating fibroblasts (A), psammoma bodies (B), and xanthogranulomatous change with cholesterol clefts (C). H \& E, original magnification $\times 4$ (A and C) and ×10 (B).

obstructive hydrocephalus, which may result in a smaller lesion becoming symptomatic sooner than it would in the parenchyma of the brain.

The presentation of CEIH and CEIVH largely varies depending on each lesion's location, size, and rate of growth. Patients present with seizures, hemiparesis, ataxia, and other focal neurological deficits. ${ }^{6,8,16,24}$ Moreover, common presentations include signs of increased intracranial pressure, such as headaches, papilledema, nausea, and vomiting. ${ }^{5,13}$ Our patient presented with headaches related to early entrapment of the temporal horn of the lateral ventricle, which resolved after complete resection. A CEIVH is probably more rare because a resolving liquefied hematoma is more readily absorbed through the ventricular system and rarely consolidates to a nidus large enough to undergo encapsulation. The age of patients presenting with CEIH or CEIVH is variable, though cases in pediatric patients seem to be quite rare. The reason for this is unknown, but perhaps the insidious growth of these hematomas causes them to take many years to become symptomatic.
Both CEIH and CEIVH can pose challenges from a radiological perspective because there are no characteristics on standard modern images that clearly distinguish them from neoplastic or vascular lesions. Prior to the modern imaging techniques of CT and MRI, skull radiography and ventriculography demonstrated only a vague hyperdensity in the brain parenchyma or ventricular system.,20 Computed tomography may show a circumscribed intracranial lesion with mass effect. ${ }^{13}$ Magnetic resonance imaging will demonstrate a well-circumscribed, variably enhancing mass with T2 signal heterogeneity and perilesional edema. ${ }^{21}$ Given the high rates of vascular malformations in cases of CEIH and CEIVH, we do recommend some form of vascular imaging, such as MR angiography. Conventional angiography is unnecessary in most cases. An abscess can usually be distinguished on the basis of restricted diffusion, which CEIH does not normally display. Given the diagnostic uncertainty based on imaging alone, biopsy or resection will likely be indicated at some point. However, given the overall benign appearance of these lesions, it would not be unreasonable to offer observation

TABLE 1. Summary of cases of CEIVH in the literature

\begin{tabular}{|c|c|c|c|c|c|c|}
\hline $\begin{array}{l}\text { Case } \\
\text { No. }\end{array}$ & $\begin{array}{l}\text { Authors } \\
\& \text { Year }\end{array}$ & $\begin{array}{l}\text { Age (yrs)/ } \\
\text { Sex }\end{array}$ & Presentation & $\begin{array}{l}\text { Imaging Findings } \\
\text { \& Lesion Location }\end{array}$ & Treatment/Outcome & Pathological Findings \\
\hline 1 & $\begin{array}{l}\text { Avol \& } \\
\quad \text { Vogel, } \\
1955\end{array}$ & $48 / \mathrm{M}$ & $\begin{array}{l}\text { Headaches, } \\
\text { nausea }\end{array}$ & $\begin{array}{l}\text { Ventriculogram: hyperdensity in rt } \\
\text { frontal horn of lat ventricle }\end{array}$ & $\begin{array}{l}\text { Rt frontal craniotomy/ } \\
\text { full recovery w/o } \\
\text { deficits }\end{array}$ & $\begin{array}{l}\text { Well-circumscribed organized } \\
\text { hematoma }\end{array}$ \\
\hline 2 & $\begin{array}{l}\text { Avol \& } \\
\text { Vogel, } \\
1955\end{array}$ & $14 / \mathrm{M}$ & $\begin{array}{l}\text { Headaches, } \\
\text { nausea, \& } \\
\text { vomiting }\end{array}$ & $\begin{array}{l}\text { Ventriculogram: large hyperdensity } \\
\text { in It lat ventricle }\end{array}$ & $\begin{array}{l}\text { Lt parietal craniotomy/ } \\
\text { full recovery w/o } \\
\text { deficits }\end{array}$ & $\begin{array}{l}\text { Well-organized \& fibrotic blood clot } \\
\text { associated w/ vascular malforma- } \\
\text { tion of choroid plexus }\end{array}$ \\
\hline 3 & $\begin{array}{l}\text { Ooba et } \\
\text { al., } \\
2003\end{array}$ & $68 / F$ & $\begin{array}{l}\text { Gait disturbance, } \\
\text { hemiparesis, } \\
\text { on warfarin }\end{array}$ & $\begin{array}{l}\text { MRI: dumbbell-shaped mass in } \\
\text { body of rt lat ventricle, } \mathrm{T} 1 \text { isoin- } \\
\text { tense, T2 mixed intensity, hetero- } \\
\text { geneous contrast enhancement }\end{array}$ & $\begin{array}{l}\text { Rt frontal craniotomy/ } \\
\text { full recovery w/ } \\
\text { resolution of gait } \\
\text { disturbance }\end{array}$ & $\begin{array}{l}\text { Organized hematoma \& granuloma- } \\
\text { tous tissue }\end{array}$ \\
\hline 4 & $\begin{array}{l}\text { Kechagias } \\
\text { et al., } \\
2010\end{array}$ & $30 / M$ & $\begin{array}{l}\text { Fever, photopho- } \\
\text { bia, diplopia, } \\
\text { cervical pain }\end{array}$ & $\begin{array}{l}\text { MRI: circular mass from roof of third } \\
\text { ventricle, T1 \& T2 hyperintense } \\
\text { w/ ring enhancement }\end{array}$ & $\begin{array}{l}\text { Rt frontal craniotomy/ } \\
\text { full recovery w/o } \\
\text { deficits }\end{array}$ & $\begin{array}{l}\text { Hematoma encapsulated by accu- } \\
\text { mulation of fibroblasts, granulation } \\
\text { tissue w/ neovascularization }\end{array}$ \\
\hline 5 & $\begin{array}{l}\text { Dey et al., } \\
2011\end{array}$ & $47 / F$ & $\begin{array}{l}\text { Numbness, } \\
\text { incoordination } \\
\text { of It hand }\end{array}$ & $\begin{array}{l}\text { MRI: bilat multilobulated masses } \\
\text { in atria of lat ventricles, T1 \& T2 } \\
\text { hyperintense w/ heterogeneous } \\
\text { contrast enhancement }\end{array}$ & $\begin{array}{l}\text { Rt parietal crani- } \\
\text { otomy/full recovery } \\
\text { w/ resolution of } \\
\text { sensation in It hand }\end{array}$ & $\begin{array}{l}\text { Firm capsule w/ hematoma of dif- } \\
\text { ferent ages, cholesterol crystals, } \\
\text { calcification \& thin-walled capillar- } \\
\text { ies c/w cavernous malformation }\end{array}$ \\
\hline
\end{tabular}

$\mathrm{c} / \mathrm{w}=$ consistent with . 
with serial imaging in an asymptomatic patient and to intervene only in the setting of rapid growth or symptom onset. We believed that resection was indicated in our patient given the headaches and early entrapment of the temporal horn. Resection has been shown to be safe and curative. Of 57 total cases of CEIH reported in the literature, 55 were surgically removed with good results. Approximately three-quarters of the patients had no deficits following surgery, and $14 \%$ were reported to have a persistent neurological deficit, but it is unclear how many of these patients had a preoperative deficit. ${ }^{26}$ Table 1 shows that among the CEIVH cases reported, all patients had successful surgical removal of the mass without postoperative deficits, as in our present case.

Choroid plexus papilloma and intraventricular cavernoma were the diagnostic considerations in our case given the patient's presentation, age, and neuroimaging findings. Preoperative MR angiography revealed a large right anterior choroidal artery but no underlying vascular malformation.

It is generally thought that these lesions do not regress on their own; we found only one case of spontaneous resorption of a CEIH. ${ }^{8}$ Surgery should not be sought in asymptomatic patients; however, if symptoms can be clearly tied to the lesion, surgery should be considered. Our operative video demonstrates the ease of removing a CEIVH given the nice tissue plane between the capsule and surrounding brain.

Histological examination is necessary for diagnosis of this entity. Grossly, the mass is usually well circumscribed and tan in color. ${ }^{10}$ There is a capsule with granulation tissue and fibroblast proliferation. Occasionally, there can be findings consistent with a cavernoma or arteriovenous malformation inside the encapsulated mass. Roda et al. theorized that a CEIH initially caused by a vascular malformation could lose gross or histological evidence of the malformation secondary to degradation of the malformation in the hematoma core over time. ${ }^{25}$ There is always deteriorating hemorrhage volume with various stages of blood breakdown in the capsule. ${ }^{4}$ In our patient, there was an organized hematoma with infiltrating fibroblasts (Fig. 5A). There were psammoma bodies (Fig. 5B), which can also be seen in normal choroid plexus histology. ${ }^{12}$ Xanthogranulomatous changes are possible within the hematoma core (Fig. 5C).

\section{Conclusions}

Both CEIH and CEIVH are benign intracranial masses that are extremely rare in pediatric patients and have a presentation that depends on lesion location and neuroimaging findings, which are nonspecific. Resection is recommended in symptomatic patients.

\section{References}

1. Aoki N, Mizuguchi K: Chronic encapsulated intracerebellar hematoma in infancy: case report. Neurosurgery 14:594597, 1984

2. Avol M, Vogel PJ: Circumscribed intraventricular hematoma simulating an encapsulated neoplasm. Bull Los Angel

Neuro Soc 20:25-29, 1955
3. Bitoh S, Hasegawa H, Fujiwara M, Nakata M, Sakurai M: Cryptic vascular malformation of the choroid plexus. Surg Neurol 16:72-76, 1981

4. Cakir E, Kuzeyli K, Usul H, Sayin OC, Kararslan G, Peksoylu B: Ruptured chronic encapsulated intracerebral hematoma in infancy: review of the literature with a case report. Childs Nerv Syst 22:436-439, 2006

5. Chen S, Zeng L, Hu Z: Progressing haemorrhagic stroke: categories, causes, mechanisms and managements. J Neurol 261:2061-2078, 2014

6. Dey M, Turner MS, Pytel P, Awad IA: A "pseudocavernoma" - an encapsulated hematoma of the choroid plexus. J Clin Neurosci 18:846-848, 2011

7. Ganapathy K: Chronic encapsulated intracerebral hematoma. Neurol India 59:504-505, 2011

8. Greiner-Perth R, Neubauer U, Schenke H: Chronic encapsulated intracerebral hematoma-a well-defined disease. Report on two cases and review of the literature. Neurosurg Rev 20:231-238, 1997

9. Guermazi A, De Kerviler E, Zagdanski AM, Frija J: Diagnostic imaging of choroid plexus disease. Clin Radiol 55:503-516, 2000

10. Hirsh LF, Spector HB, Bogdanoff BM: Chronic encapsulated intracerebral hematoma. Neurosurgery 9:169-172, 1981

11. Ikram MA, Wieberdink RG, Koudstaal PJ: International epidemiology of intracerebral hemorrhage. Curr Atheroscler Rep 14:300-306, 2012

12. Jovanović I, Ugrenović S, Vasović L, Petrović D, Cekić S: Psammoma bodies - friends or foes of the aging choroid plexus. Med Hypotheses 74:1017-1020, 2010

13. Kechagias E, Ioakimidou C, Georgakoulias N, Seretis A, Kontogeorgos G: Chronic intraventricular encapsulated hematoma in an adult: a case report. Case Rep Neurol 2:118-121, 2010

14. Kivelev J, Niemelä M, Kivisaari R, Hernesniemi J: Intraventricular cerebral cavernomas: a series of 12 patients and review of the literature. J Neurosurg 112:140-149, 2010

15. Lin CY, Chen Y, Tseng SH: Chronic encapsulated intracerebral haematoma. J Clin Neurosci 14:58-61, 2007

16. Lin SZ, Shih CJ, Wang YC, Tsai SH: Intracerebral hematoma simulating a new growth. Surg Neurol 21:459-464, 1984

17. Marutani A, Nagata K, Deguchi J, Nikaido Y, Kazuki S: A case of recurrent hemorrhages due to a chronic expanding encapsulated intracranial hematoma. Case Rep Neurol 7:173-180, 2015

18. Masuzawa T, Saito K, Shimabukuro H, Iwasa H, Sato F: Chronic encapsulated hematomas in the brain. Acta Neuropathol 66:24-28, 1985

19. Miki S, Fujita K, Katayama W, Sato M, Kamezaki T, Matsumura A, et al: Encapsulated acute subdural hematoma mimicking acute epidural hematoma on computed tomography. Neurol Med Chir (Tokyo) 52:826-828, 2012

20. Murtagh F, Baird RM: Circumscribed intraventricular hematoma in infants associated with craniosynostosis and secondary hydrocephalus. J Pediatr 59:351-355, 1961

21. Nakamizo A, Suzuki SO, Saito N, Shono T, Matsumoto $\mathrm{K}$, Onaka S, et al: Clinicopathological study on chronic encapsulated expanding hematoma associated with incompletely obliterated AVM after stereotactic radiosurgery. Acta Neurochir (Wien) 153:883-893, 2011

22. Nishiyama A, Toi H, Takai H, Hirai S, Yokosuka K, Matsushita N, et al: Chronic encapsulated intracerebral hematoma: Three case reports and a literature review. Surg Neurol Int 5:88, 2014

23. Ooba H, Kamida T, Isono M, Kobayashi H, Karashima A, Yamashita M: Chronic intraventricular encapsulated hematoma presenting unique radiological features: a case report. Surg Neurol 59:23-27, 2003 
24. Pozzati E, Giuliani G, Gaist G, Piazza G, Vergoni G: Chronic expanding intracerebral hematoma. J Neurosurg 65:611614, 1986

25. Roda JM, Carceller F, Pérez-Higueras A, Morales C: Encapsulated intracerebral hematomas: a defined entity. Case report. J Neurosurg 78:829-833, 1993

26. Rutka JT, Souweidane M, ter Brugge K, Armstrong D, Zuker $\mathrm{R}$, Clarke H, et al: Separation of craniopagus twins in the era of modern neuroimaging, interventional neuroradiology, and frameless stereotaxy. Childs Nerv Syst 20:587-592, 2004

27. Sakaida H, Sakakura M, Tochio H, Nakao K, Taniguchi A, Yabana T: Chronic encapsulated intracerebral hematoma associated with angiographically occult arteriovenous malformation-case report. Neurol Med Chir (Tokyo) 33:638642,1993

28. Takei J, Tanaka T, Yamamoto Y, Teshigawara A, Tochigi S, Hasegawa Y, et al: Chronic encapsulated expanding thalamic hematoma associated with obstructive hydrocephalus following radiosurgery for a cerebral arteriovenous malformation: a case report and literature review. Case Rep Neurol Med 2016:5130820, 2016

29. Wong AA, Henderson RD, O’Sullivan JD, Read SJ, Rajah T: Ring enhancement after hemorrhagic stroke. Arch Neurol 61:1790, 2004

30. Yuguang L, Liangwen Z, Fusheng L, Shugan Z, Xingang L,
Wandong S, et al: Chronic expanding intracerebral hematoma. J Clin Neurosci 10:680-682, 2003

\section{Disclosures}

The authors report no conflict of interest concerning the materials or methods used in this study or the findings specified in this paper.

\section{Author Contributions}

Conception and design: Wetzel. Analysis and interpretation of data: Wetzel, Wrubel. Drafting the article: all authors. Critically revising the article: all authors. Reviewed submitted version of manuscript: Wetzel.

\section{Supplemental Information \\ Videos}

Video 1. https://vimeo.com/254901372.

\section{Correspondence}

Jeremy Wetzel: Emory University School of Medicine, Atlanta, GA. jeremy.shaw.wetzel@emory.edu. 